\title{
T-Cells Show Increased Production of Cytokines and Activation Markers in Alzheimer's Disease
}

Agnes Pirker-Kees*, Christiane Schmied and Peter Dal-Bianco

Department of Neurology, Medical University of Vienna, Austria

\begin{abstract}
In Alzheimer's disease (AD), there is growing evidence of the presence of both systemic and local inflammatory processes, which might be either causative or a reaction to pathology. To characterize the systemic inflammatory profile of $A D$, we investigated peripheral blood lymphocyte subsets of $A D$ patients and age-matched Healthy Controls $(H C)$, and their production of the pro-inflammatory cytokines IL-6, IL-17, TNFa, and IFNy, together with surface expression of lymphocyte-activation-markers.

Peripheral Blood Mononuclear Cells (PBMCs) were stained ex vivo for activation markers. Intracellular cytokine staining was done after activation in vitro with CD3/CD28 for four days. Cells were analyzed using flow cytometry.

In AD patients we found significantly increased frequencies of both CD4+ and CD8+ cells producing IL-6 and IL-17, respectively. In addition we detected a significantly increased percentage of IFNy producing CD4+ cells and CD4+ cells expressing the activation markers CCR5 and HLA-DR. Taken together, our data supports the existence of a systemic inflammatory process involving also Th17-cells in AD.
\end{abstract}

Keywords: Alzheimer's disease; Cytokines; Inflammation; T-HelperCells

\section{Introduction}

Alzheimer's disease is a progressive neurodegenerative disorder characterized by irreversible impairment of cognitive and memory functions and physical deterioration. The etiology of AD is still largely unclear and thought to be a multifactorial process. Typically depositions of amyloid protein plaques between and neurofibrillary tangles within nerve cells can be detected. Theses processes stimulate microglia to produce immunological mediators, including proinflammatory cytokines and cytotoxic substances [1]. It has been shown that the inflammatory process is not restricted to the Central Nervous System (CNS), since also in peripheral blood an increase of activated $\mathrm{T}$-cells together with elevated levels of the pro-inflammatory cytokines IL-6, IL-1, and TNF-a, respectively have been detected previously $[2,3]$. Therefore we aimed to investigate the production of the pro-inflammatory cytokines IFN $\gamma$, Il-17, IL-6, and TNFa as well as the expression of various activation markers on CD4+ and CD8+ $\mathrm{T}$ cells in peripheral blood of AD-patients compared to age- matched healthy controls (HC).

\section{Methods}

\section{Patients and healthy controls}

The study was approved by the local ethics committee of the Medical University of Vienna, Austria and informed consent of all participants was obtained according to the declaration of Helsinki. Twenty four elderly individuals were enrolled in the study: 14 patients had a diagnosis of mild to moderate AD (Mini Mental State Examination (MMSE) 26-12), 10 individuals served as healthy controls. The clinical diagnosis of AD was performed at the neurology department of the Medical University of Vienna, Austria according to the NINCDS-ADRDA Alzheimer's criteria. All patients underwent complete medical and neurological workup including laboratory analysis and CT or MRI scan to exclude reversible causes of dementia. Individuals with other neurological disorders, history of malignancies, inflammatory diseases or immunomodulatory medication were not enrolled in the study. Complete blood count, C-reactive protein and erythrocyte sedimentation rate was within the normal range in all individuals during the time of the study. Antidementive medication (Acetylcholinesterase inhibitors or Memantin) had to be stable over a period of three months prior to inclusion.

\section{Blood sample collection, cell isolation and staining}

Whole blood was collected in vacutainer-tubes containing EDTA and $3 \mathrm{ml}$ were subsequently used for extracellular staining. Whole blood was incubated at $4^{\circ} \mathrm{C}$ with fluorochrome labeled monoclonal antibodies in a 1:10 dilution (CD4 FITC Mouse Anti- IgG1 Clone RPA-T4 and CD 4 APC Mouse Anti-Human IgG1 Clone L200, CD8 PE-Cy5 Mouse anti-Human IgG2a Clone 3B5, CD62L FITC Mouse Anti-Human IgG1 Clone DREG-56, CD27 FITC Mouse Anti-Human IgG1 Clone M-T271, CCR6 APC Mouse Anti-Human IgG1 Clone 11A9, CCR7 PE Rat Anti-Human IgG2a Clone 3D12, CD25 PE-Cy5 Mouse Anti-Human IgG1 Clone M-A251, CCR5 PE Mouse AntiHuman IgG2a, Clone 2D7/CCR5, CXCR3 PE-Cy5 Mouse Anti-Human IgG 1, Clone 1C6/CXR3, HLA-DR PE-Cy5 Mouse Anti-Human IgG2a Clone G46-6, and matching isotype controls for colour compensation, all obtained from Becton Dickinson biosciences, Europe) for $20 \mathrm{~min}$ in Falcon round bottom tubes (Becton Dickinson biosciences, Europe). Subsequently erythrocyte-lysis was performed for $20 \mathrm{~min}$ using BD FACS lysing solution (Beckton Dickinson biosciences, Europe) according to the manufacturers protocol. Then cells were washed twice in PBS and analyzed immediately.

*Corresponding author: Agnes Pirker-Kees, Department of Neurology, Medica University of Vienna, Waehringer Guertel 18-20, 1090 Vienna, Austria, Tel: +43 1 40400 3120; Fax: +43 140400 6215; E-mail: agnes.pirker-kees@meduniwien.ac.at

Received October 30, 2013; Accepted December 18, 2013; Published December 20, 2013

Citation: Pirker-Kees A, Schmied C, Dal-Bianco P (2013) T-Cells Show Increased Production of Cytokines and Activation Markers in Alzheimer's Disease. Brain Disord Ther 3:112. doi:10.4172/2168-975X.1000112

Copyright: $\odot 2013$ Pirker-Kees A, et al. This is an open-access article distributed under the terms of the Creative Commons Attribution License, which permits unrestricted use, distribution, and reproduction in any medium, provided the original author and source are credited. 
For intracellular cytokine staining $18 \mathrm{ml}$ whole blood was collected in heparin coated vacutainer-tubes (vacutainer tubes: Becton Dickinson \& Co., Rutherford, NJ, USA). Peripheral blood monocytes (PBMCs) were separated by density centrifugation at $4^{\circ} \mathrm{C}$ using Ficoll Hypaque solution (Sigma-Aldrich, St. Luis, Missouri). Cells were washed twice in phosphate buffered saline (PBS), then number of viable leukocytes was determined by trypan blue exclusion staining. To expand T-cells PBMCs were distributed in 96well round bottom plates (Becton Dickinson \& Co., Rutherford, NJ, USA) at a density of about $1.5 \times 10^{5}$ cells/well and incubated for four days in unspecific $t$-cell polarizing conditions using RPMI-1640 medium (Invitrogen, GIBCO ${ }^{\circ}$ ) containing $1 \mathrm{ng} / \mathrm{ml} \mathrm{CD} 3$ and $1 \mathrm{ng} / \mathrm{ml} \mathrm{CD} 28,5 \%$ each of HEPES, glutamate, non-essential amino-acids, pyruvate, and heat-inacativated $10 \%$ human serum at $37^{\circ} \mathrm{C}$ in a humidified $5 \% \mathrm{CO}_{2}$ atmosphere. We identified a stimulation time of 96 hours as being optimal for the reliable detection of IL-17-producing T cells. At day 4, cells were restimulated with $10 \mathrm{ng} / \mathrm{ml}$ PMA, $1 \mathrm{ng} / \mathrm{ml}$ Ionomycine (both Sigma Aldrich, St. Luis, Missouri) and $5 \mathrm{ng} / \mathrm{ml}$ GolgiPlug (Beckton Dickinson biosciences, Europe) for 5 hours. Cells were then harvested into 1.5 ml FACS tubes, fixed and permeabilized (BD Cytofix/Cytoperm kit, Beckton Dickinson Biosciences, Europe), according to manufacturers protocol. To avoid unspecific staining, cells were then blocked with beriglobin $3 \mathrm{mg} / \mathrm{ml}$ (CSL Behring, Austria).

Then cells were stained at $4^{\circ} \mathrm{C}$ for $30 \mathrm{~min}$ for CD4 APC Mouse Anti-Human IgG1 Clone L200, CD8 PE-Cy5.5 Mouse Anti-Human IgG2 Clone 3B5, TNF-alpha PE Mouse Anti-Human IgG2 Clone MAb11, IL-6 PE Rat-Anti-Human IgG 2a Clone MQ2-6A3, IFN $\gamma P E$ Mouse Anti-Human IgG1 Clone B27 (all Beckton Dickinson bioscience, Europe), and IL-17 FTIC Mouse Anti-Human IgG1 Clone eBio64DEC17 (eBioscience, Austria) as well as matched isotype-controls. All antibodies were used at a diluation of 1:10. Cells were washed twice at $4^{\circ} \mathrm{C}$ in $\mathrm{PBS}$ and analyzed immediately by flow cytometry [4-6].

\section{Flow cytometric analyses}

Analyses of ten-thousand cells per acquisition were performed using a 4-colour Beckton Dickinson FACS Calibur cytometer running on CellQuest Pro software. Isotype controls and single stained preparations were first run for color compensation. Linear amplifiers were used for forward and side scatters and logarithmic amplifiers for fluorescence labeled channels. Lymphocytes were identified in the forward and side scatter first and gated on either CD4 or CD8, and further gated on extracellular activation markers or cytokines. Results are given as proportion of cells expressing the activation marker or cytokine within the CD4 or CD8 subset as well as Mean Fluorescence Intensity (MFI).

\section{Statistical methods}

Normal distribution of each variable was tested using KolmogorovSmirnov-test. Data are expressed as mean \pm standard deviation. Group comparisons between AD and HC were done using Student's t-test for normally distributed variables and Mann-Whithney-U-test for not normally distributed variables. Correlations were assessed using Spearman's correlation-coefficient. A p-value $<0.05$ was considered statistically significant. Logistic regression analysis was done including $\mathrm{AD}$ as dependent variable, CCR5, HLA-DR, CD4+IL6, CD8+IL6, CD4+Ifn-g, CD4+IL-17 and CD8+IL17 as variables influencing AD, and age and sex as dummy variables to identify possible confounders. Data analysis was performed using SPSS version 15.0 (SPSS, Inc. Chicago, Illinois, USA).

\section{Results}

We included $14 \mathrm{AD}$ (7 female, mean age $70 \mathrm{y} \pm 4.5)$ and $10 \mathrm{HC}$ (5 female, mean age 73y \pm 5.3 ). Mean MMSE was $21(12-26)$ in AD and 30 in HC. All AD were on stable dosage of one of the following cholinesterase inhibitors: galantamine, rivastigmine and donezepil and one patient had additional memantine medication (Table 1). Absolute lymphocyte count was obtained from routine laboratory examination and did not differ between $\mathrm{AD}$ an HC. The CD4+ and CD8+ fractions were assessed by flow-cytometric analyses and a CD4/ $\mathrm{CD} 8$ ratio was calculated. No differences between $\mathrm{AD}$ and $\mathrm{HC}$ and no correlations with MMSE or age were observed regarding the CD4/CD8 ratio. Surface activation markers and chemokine-receptors of CD4+ and CD8+ cells were assessed ex vivo by flow-cytometry. Within the CD4+ subset cells of AD expressed significantly more often HLA-DR $(26.7 \% \pm 8.7$ vs. $14.5 \% \pm 6.2$, Student's t-test, $\mathrm{p}=0.008)$. Amongst the chemokine-receptors CCR5, CCR6, and CCR7, only the frequency of cells expressing CCR5 was significantly increased in $\mathrm{AD}(33.2 \% \pm 14.1$ in AD vs. $19.6 \pm 10.3$ in $\mathrm{HC}, \mathrm{MWU}, \mathrm{p}=0.022$ ). CD69 was also increased on $\mathrm{CD} 4+$ in $\mathrm{AD}$, but missed statistical significance $(5.7 \% \pm 5.1$ in $\mathrm{AD}$ vs. $2.5 \% \pm 1.5$ in HC, Student's t-test, $\mathrm{p}=0.088$ ). Expression of the other activation markers tested CD25, CD27, CD62L, and CXCR3 did not differ between $\mathrm{AD}$ and HC. Amongst the CD8+ subset the activation markers and chemokine-receptors CCR5, CCR7, CD27, CD58, and CXCR3 did not differ significantly between $\mathrm{AD}$ and HC (Figure 1). Cytokine-production of TNFa, IL-6, IFN $\gamma$, and IL-17 in CD4+ and CD8+ cells was then assessed by flow-cytometry after 4 day stimulation with CD3/CD28.

The percentage of CD4+ and CD8+ cells producing IL-17 was higher in $\mathrm{AD}$ than in $\mathrm{HC}(\mathrm{CD} 4+6.2 \% \pm 2.7$ vs. $1.5 \% \pm 0.6$, Student's t-test, $\mathrm{p}<0.001$ and $\mathrm{CD} 8+9.6 \% \pm 4.7$ vs. $2.6 \% \pm 1.3$, Student's t-test,

\begin{tabular}{|c|c|c|c|c|}
\hline Age/Sex & AD/HC & MMSE & CRP & WBC \\
\hline $60 / \mathrm{m}$ & $\mathrm{HC}$ & 30 & $<1 \mathrm{mg} / \mathrm{dl}$ & $<10 \mathrm{G} / \mathrm{l}$ \\
\hline $85 / f$ & $\mathrm{HC}$ & 30 & $<1 \mathrm{mg} / \mathrm{dl}$ & $<10 \mathrm{G} / \mathrm{l}$ \\
\hline $81 / \mathrm{m}$ & $\mathrm{HC}$ & 30 & $<1 \mathrm{mg} / \mathrm{dl}$ & $<10 \mathrm{G} / \mathrm{l}$ \\
\hline $71 / f$ & $\mathrm{HC}$ & 30 & $<1 \mathrm{mg} / \mathrm{dl}$ & $<10 \mathrm{G} / \mathrm{l}$ \\
\hline $77 / \mathrm{m}$ & $\mathrm{HC}$ & 30 & $<1 \mathrm{mg} / \mathrm{dl}$ & $<10 \mathrm{G} / \mathrm{l}$ \\
\hline $60 / f$ & $\mathrm{HC}$ & 30 & $<1 \mathrm{mg} / \mathrm{dl}$ & $<10 \mathrm{G} / \mathrm{l}$ \\
\hline $58 / f$ & $\mathrm{HC}$ & 30 & $<1 \mathrm{mg} / \mathrm{dl}$ & $<10 \mathrm{G} / \mathrm{l}$ \\
\hline $77 / \mathrm{m}$ & $\mathrm{HC}$ & 30 & $<1 \mathrm{mg} / \mathrm{dl}$ & $<10 \mathrm{G} / \mathrm{l}$ \\
\hline $79 / f$ & $\mathrm{HC}$ & 30 & $<1 \mathrm{mg} / \mathrm{dl}$ & $<10 \mathrm{G} / \mathrm{l}$ \\
\hline $73 / \mathrm{m}$ & $\mathrm{HC}$ & 30 & $<1 \mathrm{mg} / \mathrm{dl}$ & $<10 \mathrm{G} / \mathrm{l}$ \\
\hline $71 / \mathrm{m}$ & $A D$ & 19 & $<1 \mathrm{mg} / \mathrm{dl}$ & $<10 \mathrm{G} / \mathrm{l}$ \\
\hline $63 / \mathrm{m}$ & $A D$ & 15 & $<1 \mathrm{mg} / \mathrm{dl}$ & $<10 \mathrm{G} / \mathrm{l}$ \\
\hline $63 / \mathrm{m}$ & $A D$ & 20 & $<1 \mathrm{mg} / \mathrm{dl}$ & $<10 \mathrm{G} / \mathrm{l}$ \\
\hline $63 / \mathrm{m}$ & $A D$ & 26 & $<1 \mathrm{mg} / \mathrm{dl}$ & $<10 \mathrm{G} / \mathrm{l}$ \\
\hline $67 / f$ & $A D$ & 18 & $<1 \mathrm{mg} / \mathrm{dl}$ & $<10 \mathrm{G} / \mathrm{l}$ \\
\hline $69 / \mathrm{m}$ & $A D$ & 23 & $<1 \mathrm{mg} / \mathrm{dl}$ & $<10 \mathrm{G} / \mathrm{l}$ \\
\hline $74 / f$ & $A D$ & 23 & $<1 \mathrm{mg} / \mathrm{dl}$ & $<10 \mathrm{G} / \mathrm{l}$ \\
\hline $75 / f$ & $A D$ & 22 & $<1 \mathrm{mg} / \mathrm{dl}$ & $<10 \mathrm{G} / \mathrm{l}$ \\
\hline $68 / f$ & $A D$ & 12 & $<1 \mathrm{mg} / \mathrm{dl}$ & $<10 \mathrm{G} / \mathrm{l}$ \\
\hline $75 / f$ & $A D$ & 21 & $<1 \mathrm{mg} / \mathrm{dl}$ & $<10 \mathrm{G} / \mathrm{l}$ \\
\hline $70 / \mathrm{m}$ & $A D$ & 21 & $<1 \mathrm{mg} / \mathrm{dl}$ & $<10 \mathrm{G} / \mathrm{l}$ \\
\hline $68 / \mathrm{m}$ & $A D$ & 12 & $<1 \mathrm{mg} / \mathrm{dl}$ & $<10 \mathrm{G} / \mathrm{l}$ \\
\hline$--/ m$ & $A D$ & 22 & $<1 \mathrm{mg} / \mathrm{dl}$ & $<10 \mathrm{G} / \mathrm{l}$ \\
\hline $70 / f$ & $A D$ & 26 & $<1 \mathrm{mg} / \mathrm{dl}$ & $<10 \mathrm{G} / \mathrm{l}$ \\
\hline
\end{tabular}

Table 1: Baseline characteristics 
$\mathrm{p}<0.001)$. The same result could be obtained regarding IL-6 producing CD4+ and CD $8+$ cells $(C D 4+4.7 \% \pm 1.7$ vs. $2.4 \% \pm 0.7$, Student's t-test, $\mathrm{p}<0.001$ and $\mathrm{CD} 8+6.2 \% \pm 3$ vs. $2.6 \% \pm 1.4$, Student's t-test, $\mathrm{p}=0.005)$. The percentage of cells producing IFN $\gamma$ was increased in AD only in the CD4+ subset $(8.4 \% \pm 3.6$ vs. $4.7 \% \pm 2.3$ Student's t-test, $\mathrm{p}=0.001)$. Percentage of cells producing TNFa did not differ between $\mathrm{AD}$ and $\mathrm{HC}$ neither in the CD4+ nor in the CD8+ subset. The MFI of the above mentioned cytokines did not differ between $\mathrm{AD}$ and $\mathrm{HC}$ in the CD4+ and CD8+ subsets (Figure 2).

Age and sex did not correlate with percentage of the cytokine producing CD4+ and CD8+ cells. Regarding MMSE only percentage of CD4+IL-17+ cells correlated with MMSE when testing all subjects included in the study (Spearman, $\mathrm{p}=0,023$ ), but not in $\mathrm{AD}$ alone.

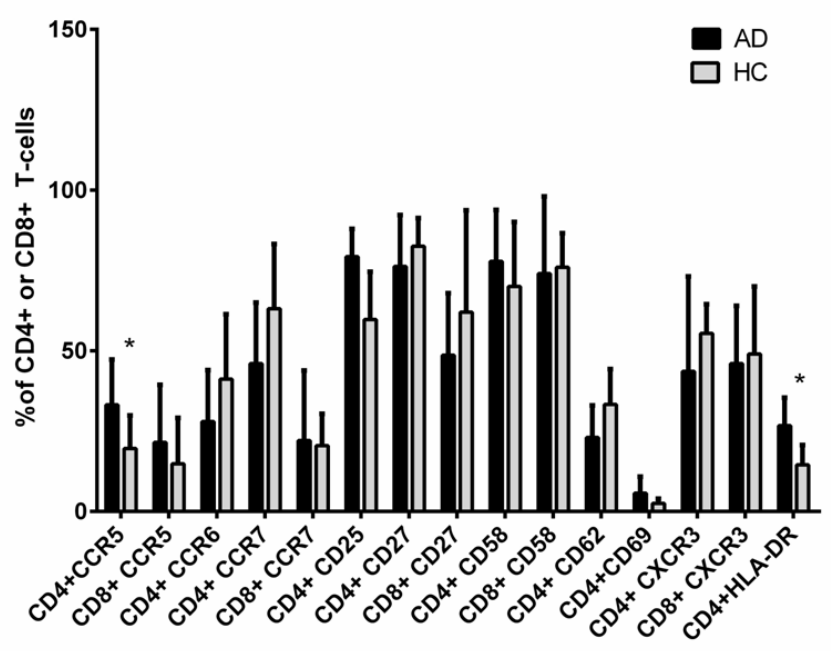

Figure 1: Amount of circulating CD4+ and CD8+ T- cells with surface expression of activation markers and chemokine-receptors in Alzheimer's disease (black columns) and healthy controls (grey columns) given as percentages of either CD4+ or CD8+ cells (mean), whiskers indicate standard deviation, * marks significant differences $(p<0.05)$

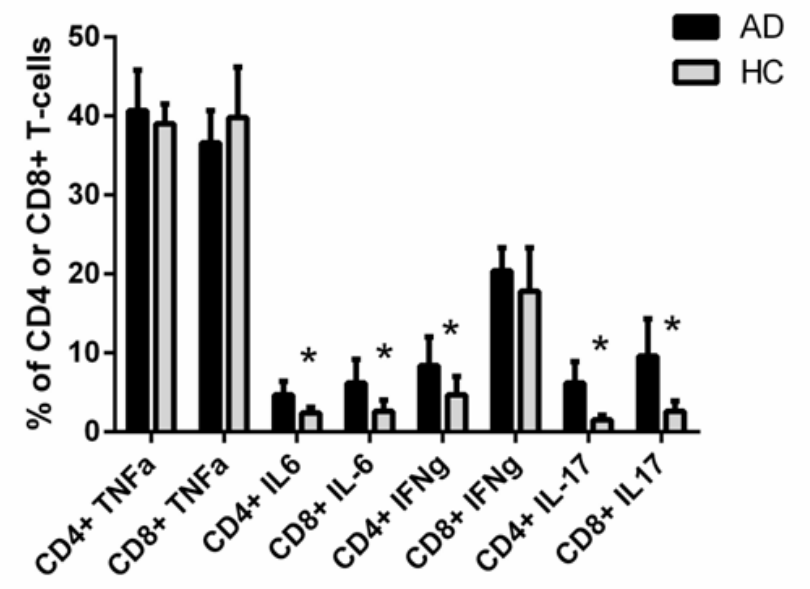

Figure 2: Frequency of cytokine producing CD4+ and CD8+ T-cells in Alzheimer's disease (black columns) and healthy controls (grey columns), given as percentage of CD4+ or CD8+ T-cells (mean), whiskers indicate standard deviation, * marks significant difference $(p<0.05)$
Notably, the frequency of cells expressing HLA-DR correlated with the percentage of CD4+ cells producing IFN $\gamma$, Il-6, and Il-17 (Spearman, $\mathrm{p}=0,002, \mathrm{p}=0,049$, and $\mathrm{p}=0,036$ ).

When performing logistic regression modelling including CD4+IFN $\gamma+, \quad$ CD4+IL6+, CD8+IL6+, CD4+IL17+, CD8+IL17+, CD4+CCR5+, and CD4+HLA-DR+, CD4+IL17+ (all increased in AD) as well as age and sex as control variables, only CD4+IL17+ remained significantly associated with $\mathrm{AD}(\mathrm{p}=0.009)$.

Taken together, these results suggests a pro-inflammatory disposition in $\mathrm{AD}$ consisting of an increased expression of the activation markers HLA-DR and CCR 5 on CD4+ cells and an increased proportion of lymphocytes able to produce IL-17, IL-6 and IFN-g.

\section{Discussion}

There is an emerging concept that alterations of both innate and acquired branches of the immune system [7] contribute to pathogenesis of $\mathrm{AD}$. However, to date, there is no general consensus regarding alterations of lymphocyte subsets in $\mathrm{AD}$ patients. We investigated activation markers and cytokine production of PBMCs in AD and HC. Interestingly we detected a characteristic pro-inflammatory profile in $\mathrm{AD}$ consisting of an increase of activated CD4+ lymphocytes with surface-expression of HLA-DR and CCR5 together with increased percentages of circulating lymphocytes producing IL-17, Il-6, and IFN $\gamma$, while total amounts of CD4+ and CD8+ cells were not altered in $\mathrm{AD}$.

\section{Lymphocyte activation markers in AD}

CCR5 was increased on CD4+ cells in AD ex vivo both in our investigation as well as previously shown after stimulation with $\mathrm{A} ß[3,8]$. This fits to the concept of a pro-inflammatory process accompanying $\mathrm{AD}$. T-cells are able to respond to chemokines produced in the brain and by HBMECs via CCR5. Increased expression of CCR 5 might explain their migration into the brain in $\mathrm{AD}$ [9] as the CCR5ligand CCL3 is expressed on astrocytes and microglia in AD [10]. Furthermore the pro-inflammatory cytokines TNFa, IL- 1 and IFN $\gamma$ have been found to be increased in peripheral blood of $\mathrm{AD}$ patients. They can further induce the expression of the CCR5-ligands CCL3, CCL4 and CCL5, respectively in vitro on human brain microvascular endothelial cells (HBMECs) [11]. In mouse-mesangial cells, Il-17 elicited the expression of the CCR5 ligand CCL3 [12], however this has not yet been investigated for HBMECs.

The other activation marker found to be increased on CD4+ cells in our investigation was HLA-DR. HLA-DR initiates immune reactions by binding antigens to T-cells. The increased number of CD4+ cells expressing HLA-DR in AD is consistent with previous reports, where the expression of HLA-DR on circulating T-cells in $\mathrm{AD}$ as well as post mortem in brains of $\mathrm{AD}$ was associated with disease severity [2,13-15]. We found no correlation between expression of HLA-DR and MMSE, which might be due to the relatively small sample size.

\section{Pro-inflammatory cytokines}

We found IL-17 to be significantly increased in CD4+ cells of AD patients vs. HC. Amongst all pro-inflammatory cytokines increased in $\mathrm{AD}, \mathrm{IL}-17$ is of special interest, as it bears a manifold of biological roles well compatible with what is currently known about inflammation in $\mathrm{AD}$. The relevance of IL-17 in peripheral blood might differ from intracerebral IL-17, as it was shown to be reduced in cerebrospinal fluid in $\mathrm{AD}$ and other neurodegenerative disorders [16]. 
Peripheral blood IL-17 can weaken tight junctions of the bloodbrain-barrier to facilitate leukocyte entry into the CNS, and it induces production of the pro-inflammatory cytokines Il-6, TNFa, and IL-1 all previously shown to be increased in peripheral blood of $\mathrm{AD}[11,17]$.

In $\mathrm{AD}$ stimulation of PBMCs with $\mathrm{A} B$ lead to an increased production of the Th17-cytokines IL-21 and IL-22 (but not IL-17) in CD4+ cells and to an increased production of IL-6 and IL-23 in macrophages/monocytes, both cytokines important for differentiation and stabilization of Th17 cells [18]. In contrast, we found an increased percentage of CD4+ cells producing IL-17. This discrepancy requires further investigation, but it might be at least partially explained by patient selection and methodological differences, as we used only unspecific stimulation with CD3/CD28. Still, our findings together with existing literature show an increased underlying proportion of cells able to produce Th17-related cytokines in AD suggesting that Th17 cells might be of some relevance in the inflammatory process in AD.

Less is known about the biological function of CD8+ Tc17 cells, except their appearance in various diseases (e.g. psoriasis, malignancies [19]. CD8+ cells were not altered in our investigation in general, but the relative increase of the $\mathrm{CD} 8+\mathrm{Tc} 17$-cells needs further investigation. The increased amount of CD4+ and CD8+ T-cells producing IL- 6 and IFN $\gamma$, even without antigen-specific stimulation, is consistent with previous data and further supports the hypothesis of inflammation being involved at some stage in the natural disease course of $\mathrm{AD}$ [3].

Nevertheless, data about alterations of the immune-system in $\mathrm{AD}$ are complex and controversial, and it remains to be shown, if systemic inflammation is an underlying pathogenic mechanism or rather an epiphenomenon due to release of intracerebral Aß42 and cytokines in AD. Although our study is an observational one with a limited number of subjects, it revealed significant results supporting the existence and importance of a systemic inflammatory process, characterized by an increased expression of HLA-DR and CCR 5 and increased percentages of T-cells capable of production of IL-17, IFN $\gamma$ and IL-6. How increased inflammatory activity might reflect disease progression and/or disease severity is an interesting question and requires future investigations. Characterizing AD using inflammatory-profiling might help to identify selected patient groups for clinical trials and immune-modulatory therapeutic strategies. Embedded in this context our investigation may serve as an impulse for longitudinal studies including a focus on Th17cells.

\section{References}

1. Speciale L, Calabrese E, Saresella M, Tinelli C, Mariani C et al. (2007) Lymphocyte subset patterns and cytokine production in Alzheimer's disease patients. Neurobiol Aging 28: 1163-1169.

2. Shalit F, Sredni B, Brodie C, Kott E, Huberman M (1995) T lymphocyte subpopulations and activation markers correlate with severity of Alzheimer's disease. Clin Immunol Immunopathol 75: 246-250.

3. Pellicanò M, Bulati M, Buffa S, Barbagallo M, Di Prima A, et al. (2010) Systemic immune responses in Alzheimer's disease: in vitro mononuclear cell activation and cytokine production. J Alzheimers Dis 21: 181-192.
4. Jandus C, Bioley G, Rivals JP, Dudler J, Speiser D, et al. (2008) Increased numbers of circulating polyfunctional Th17 memory cells in patients with seronegative spondylarthritides. Arthritis Rheum 58: 2307-2317.

5. Hedegaard CJ, Krakauer M, Bendtzen K, Lund H, Sellebjerg F, et al. (2008) T helper cell type 1 (Th1), Th2 and Th17 responses to myelin basic protein and disease activity in multiple sclerosis. Immunology 125: 161-169.

6. Rodrigues-Díez R, Rodrigues-Díez RR, Rayego-Mateos S, Suarez-Alvarez B Lavoz C, et al. (2013) The C-terminal module IV of connective tissue growth factor is a novel immune modulator of the Th17 response Lab Invest 93: 812 . 824

7. Britschgi M, Wyss-Coray $T$ (2007) Systemic and acquired immune responses in Alzheimer's disease. Int Rev Neurobiol 82: 205-233.

8. Gaskin F, Finley J, Fang Q, Xu S, Fu SM (1993) Human antibodies reactive with beta-amyloid protein in Alzheimer's disease. J Exp Med 177: 1181-1186.

9. Shukaliak JA, Dorovini-Zis K (2000) Expression of the beta-chemokines RANTES and MIP-1 beta by human brain microvessel endothelial cells in primary culture. J Neuropathol Exp Neurol 59: 339-352.

10. Xia MQ, Qin SX, Wu LJ, Mackay CR, Hyman BT (1998) Immunohistochemical study of the beta-chemokine receptors CCR3 and CCR5 and their ligands in normal and Alzheimer's disease brains. Am J Pathol 153: 31-37.

11. Chui R, Dorovini-Zis K (2010) Regulation of CCL2 and CCL3 expression in human brain endothelial cells by cytokines and lipopolysaccharide. $J$ Neuroinflammation 7: 1 .

12. Paust HJ, Turner JE, Steinmetz OM, Peters A, Heymann F, et al. (2009) The IL-23/Th17 axis contributes to renal injury in experimental glomerulonephritis. J Am Soc Nephrol 20: 969-979.

13. Ikeda T, Yamamoto K, Takahashi K, Yamada M (1991) Immune system associated antigens on the surface of peripheral blood lymphocytes in patients with Alzheimer's disease. Acta Psychiatr Scand 83: 444-448.

14. Xue SR, Xu DH, Yang XX, Dong WL (2009) Alterations in lymphocyte subse patterns and co-stimulatory molecules in patients with Alzheimer disease. Chin Med J (Engl) 122: 1469-1472.

15. Rogers J, Luber-Narod J, Styren SD, Civin WH (1988) Expression of immune system-associated antigens by cells of the human central nervous system relationship to the pathology of Alzheimer's disease. Neurobiol Aging 9: 339349

16. Hu WT, Chen-Plotkin A, Arnold SE, Grossmann M, Clark CM et al. (2010) Biomarker discovery for Alzheimer's disease, frontotemporal loba degeneration, and Parkinson's disease. Acta Neuropahtol 120: 385-399

17. Heneka MT, O'Banion MK (2007) Inflammatory processes in Alzheimer's disease. J Neuroimmunol 184: 69-91.

18. Saresella M, Calabrese E, Marventano I, Piancone F, Gatti A, et al. (2011) Increased activity of Th-17 and Th-9 lymphocytes and a skewing of the postthymic differentiation pathway are seen in Alzheimer's disease. Brain Behav Immun 25: 539-547.

19. Tesmer LA, Lundy SK, Sarkar S, Fox DA (2008) Th17 cells in human disease. Immunol Rev 223: 87-113. 